\title{
Differences in the support needs of children with developmental disabilities among groups of medical and behavioral needs
}

\author{
Víctor B Arias ${ }^{1}$, Virginia Aguayo ${ }^{\text {Corresp., } 1}$, Miguel A Verdugo ${ }^{1}$, Antonio M Amor ${ }^{1}$ \\ ${ }^{1}$ Institute on Community Integration, Faculty of Psychology, University of Salamanca, Salamanca, Spain \\ Corresponding Author: Virginia Aguayo \\ Email address: aguayo@usal.es
}

Background/aims. Medical and behavioral needs are relevant in organizing and providing support strategies that improve the quality of life for children, along with their families. The present study aims to examine the impact of medical and behavioral needs on the need for support of children with disabilities.

Methods. Health and education professionals were interviewed using the Supports Intensity ScaleChildren's version to estimate the support needs of 911 children and adolescents (5-16 years) with an intellectual disability, including 55.32\% with an additional disability. For data analysis, a model for measuring support needs was specified, consisting of seven support needs factors and three method factors. In estimating the model, four groups of medical and behavioral needs were considered. The factor scores' means of the groups were compared through t-tests.

Results. Medical and behavioral needs had an impact on overall support needs. Differences were found in all support domains for medical needs. The greatest influence of behavioral needs was found in the Social and School participation areas but was indistinguishable between the mild and moderate levels of needs.

Conclusions. Medical and behavioral needs greatly affect the need for support in a child's daily life, so they need to be considered a priority for support services. The importance of standardized assessments is emphasized to help develop support strategies. 


\section{Differences in the support needs of children with}

2 developmental disabilities among groups of medical

3 and behavioral needs

4

5

Víctor B. Arias ${ }^{1}$, Virginia Aguayo ${ }^{1}$, Miguel A. Verdugo ${ }^{1}$, Antonio M. Amor ${ }^{1}$

${ }^{1}$ Institute on Community Integration, Faculty of Psychology, University of Salamanca, Salamanca, Spain

Corresponding Author:

Virginia Aguayo ${ }^{1}$

Avda. de la Merced, 109-131, Salamanca, 37005, Spain

Email address: aguayo@usal.es

\section{Abstract}

Background/aims. Medical and behavioral needs are relevant in organizing and providing support strategies that improve the quality of life for children, along with their families. The present study aims to examine the impact of medical and behavioral needs on the need for support of children with disabilities.

Methods. Health and education professionals were interviewed using the Supports Intensity Scale-Children's version to estimate the support needs of 911 children and adolescents (5-16 years) with an intellectual disability, including $55.32 \%$ with an additional disability. For data analysis, a model for measuring support needs was specified, consisting of seven support needs factors and three method factors. In estimating the model, four groups of medical and behavioral needs were considered. The factor scores' means of the groups were compared through t-tests.

Results. Medical and behavioral needs had an impact on overall support needs. Differences were found in all support domains for medical needs. The greatest influence of behavioral needs was found in the Social and School participation areas but was indistinguishable between the mild and moderate levels of needs.

Conclusions. Medical and behavioral needs greatly affect the need for support in a child's daily life, so they need to be considered a priority for support services. The importance of standardized assessments is emphasized to help develop support strategies. 


\section{Introduction}

35 A person's need for support arises when the context demands a task that is beyond their abilities. Depending on their skills and the facilitators available in the environment, the intensity of support required will vary. The pattern and intensity of support that a person needs to participate in activities of daily living are called "support needs" (Schalock et al., 2010; Thompson et al., 2009). Understanding persons by their support needs, rather than by their impairments, is related to an ecological-contextual approach to disability and the adoption of a support model. This approach emphasizes the idea that everyone needs support, and what differentiates some individuals from others is the intensity of support required to participate in activities of daily living (Thompson et al., 2009).

The support model is increasingly applied in the field of intellectual and developmental disabilities (IDD). Individualized support plans are developed considering a person's support needs profile, combined with their wishes and goals (Schalock, 2018; Thompson et al., 2018; Walker et al., 2018). Furthermore, aggregated data on the support needs profiles of many individuals are useful in improving the effectiveness and efficiency of organizational and state resource allocation (Chou et al., 2013; Giné et al., 2014; van Loon et al., 2013). The support model is also extending because it offers a way to integrate and organize support strategies aligned with desired quality of life outcomes, allowing for the evaluation of the suitability of undertaken actions (Lombardi et al., 2016; Verdugo, 2018).

The support model considers five elements in assessing the individual's support needs (Thompson et al., 2004): personal competence (defined as intellectual and adaptive behavioral skills), the number and complexity of environments in which the person participates, the number and complexity of activities, the presence of exceptional medical needs, and the presence of exceptional behavioral needs. Thus, one individual may have higher support needs than another because of additional medical and behavioral needs or the existence of restricted environments for participation (van Gorp et al., 2019; van Timmeren et al., 2017; Zijlstra \& Vlaskamp, 2005). Furthermore, persons with medical and behavioral needs might require greater support than those with fewer limitations, including a wider range of resources to be deployed.

The presence of medical and behavioral problems in the severity of a disability has been well established, as it suggests important implications for the planning of support systems. Regarding the family, parenting becomes even more complicated, causing greater stress and the urgent need to care for the well-being of the individual and their family (Kyzar et al., 2012). Concerning school, teachers are required to take on the roles of health professionals along with their educational competencies, so they often work outside of their field of expertise (Petitpierre et al., 2007). Addressing extensive support needs is also a challenge for health systems because of the difficulty in identifying needs (Bjorgaas et al., 2012; Mazza et al., 2019) and mainly the lack of consistent terminology (Nakken \& Vlaskamp, 2007), which hinders the allocation of services, especially in the case of severe disabilities. 
72 From a support model, a person will need maximum levels of support given certain medical

73 conditions and challenging behaviors, regardless of the intensity of the support needed in other

74 areas of daily living (Thompson et al., 2002). Although the relationship seems clear, some

75 authors (Seo et al., 2017) advocate examining the impact of medical and behavioral needs in

76 different contexts to identify priorities in the provision of support. Surprisingly, this research is

77 scarce, especially in children with IDD, and using a standardized measure of support needs.

78 Bertoncelli et al. (2019) studied factors associated with severe intellectual disabilities in

79 adolescents with cerebral palsy. They found that youths who require more medical support had

80 more severe disabilities but did not require much behavioral support. It seems that support needs,

81 especially relating to medical support, increase with the presence of other comorbidities and

82 health problems, which is common in more severe disabilities where there is a high co-

83 occurrence of functional motor and intellectual impairments and limitations. Similarly, in a

84 sample of 1,614 children with autism and intellectual disabilities, Shogren et al. (2017) found

85 low medical needs and more behavioral needs. The authors related this finding to the increased

86 risk of those behavioral needs in response to challenging contexts for children with autism. To

87 our knowledge, no studies have analyzed the impact of medical and behavioral needs,

88 considering different levels of intensity and assessing children with different IDD.

\section{Objectives of the study}

90 The current study aims to analyze the impact of medical and behavioral needs on overall support

91 needs in a sample of children with IDD. Consistent with other studies, we expect that a higher

92 intensity of medical and behavioral support needs will lead to greater support needs overall.

93 However, our goal is to investigate the nature of this relationship (i.e., whether it is linear or

94 nonlinear) and to identify differences in the impact of exceptional needs across different domains

95 of support. We also aim to analyze the effects of medical and behavioral needs on support need

96 scores separately by considering different intensity groups (i.e., no needs, low needs, moderate

97 needs, and high needs).

\section{Materials \& Methods}

\section{Participants}

100 The voluntary collaboration of centers and entities specialized in IDD was requested. The

101 selection criteria included the provision of support services to (a) children and adolescents

102 between the ages of 5 and 16, and (b) having an IDD diagnosis.

103 The sample was composed of 911 children and adolescents (ages ranging from 5-16 years, $M=$ $10411.15, S D=3.42)$, and predominantly male participants $(61.91 \%)$. Most of the individuals lived 105 with their parents (95.28\%) and attended special education schools (67.18\%). They belonged to

10613 Spanish regions, including Castile and Leon (23.27\%), Andalusia (15.70\%), and the

107 Community of Madrid (13.50\%); their native language was Spanish (93.96\%).

108 All participants had an intellectual disability, 44.24\% of them as the primary diagnosis (Table 1).

109 Intellectual disability was concomitant with cerebral palsy, autism, or sensory disability in 
$11038.53 \%$ of cases, and three conditions were present in the $16.79 \%$ of children. Levels of 111 intellectual functioning were collected from the children's medical records.

112 The information about the children's support needs was provided by direct-care professionals, 113 comprised mostly of teachers (64.54\%), psychologists (5.82\%), social educators (5.05\%), and 114 physical therapists $(4.72 \%)$.

\section{Instrument}

116 To quantify and describe the profile of support needs, we used the Supports Intensity Scale-

117 Children's version (SIS-C; Thompson et al., 2016) adapted to Spanish (Verdugo et al., 2014, 118 2016). The SIS-C is an objective tool that aims to assess the extraordinary support needs that 119 youngsters (between 5 and 16 years old) with IDD need to participate in different activities of 120 their daily lives successfully. The SIS-C is completed in the form of an interview by a qualified 121 professional trained in its application, and its duration varies between 45 and 60 minutes. The 122 respondents are individuals who have some sort of relationship with the child (e.g., direct care 123 professionals or relatives), so their support needs can be estimated accurately.

124 The SIS-C is possibly the most widely tool used for standardized assessment of support needs 125 (AAIDD, n.d.). Its development emerged from a review of the scientific literature and Q-test 126 methodology (Thompson et al., 2002, 2014). The original scale analysis was performed with 127 4,015 students, and good psychometric properties were obtained exceeding values of .90 in 128 Cronbach's alpha (Thompson et al., 2016). Moreover, the structure of seven correlated support 129 needs factors and three methods factors has been increasingly supported (Aguayo et al., 2019; 130 Seo et al., 2016; Seo et al., 2017; Verdugo et al., 2019). In all standardization studies, including 131 those from other countries, trained professionals were responsible for collecting the participants' 132 data (Giné et al., 2017; Thompson et al., 2016; Verdugo et al., 2016).

133 The SIS-C consists of two sections: (1) exceptional medical and behavioral needs and (2) support 134 needs in different domains of the person's life.

\section{Exceptional medical and behavioral needs}

136 This section is divided into two sets of activities, which are estimated on a scale of $0-2$, with 0 137 being no support needed, 1 being some support needed, and 2 being extensive support needed.

138 The rating in this section is not included in the SIS-C standardized scores, but it is taken as 139 information that might influence the supports delivered in the support domains (Thompson et al., 140 2016). The set of medical needs consists of a total of 18 activities, which are related to 141 respiratory care (e.g., postural drainage), feeding assistance (e.g., use of nasogastric tube), skin 142 care (e.g., turning or positioning), or other forms of care (e.g., seizure management, dialysis). 143 The set of behavioral needs includes 13 activities, either directed at individuals (e.g., prevention 144 of injuries to others) or oneself (e.g., self-injury). Besides, these activities include inappropriate 145 sexual behavior (e.g., sexual aggression) as well as other issues (e.g., preventing tantrums, 146 wandering). 


\section{Support needs in different domains}

148 This section consists of 61 activities distributed in seven support domains, as follows: Home life 149 (9 items; e.g., sleeping), Community and neighborhood (8 items; e.g., shopping), School 150 participation (9 items; e.g., participating in activities in common school areas), School learning 151 (9 items; e.g., learning academic skills), Health and safety (8 items; e.g., maintaining physical 152 fitness), Social activities (9 items; e.g., making and keeping friends), and Advocacy (9 items; 153 e.g., expressing preferences). The support for each activity is estimated through three indicators: 154 the type of support needed, the frequency of support required, and the daily support time. The 155 three indicators are scored separately and based on a Likert-type scale ranging from 0 to 4 , where 156 higher numerical values indicate the greater intensity of support. The seven-dimensional 157 structure has been well established (Seo et al., 2016; Verdugo et al., 2016, 2019).

\section{Procedure}

159 This research was conducted under the principles of the Declaration of Helsinki (World Medical 160 Association, 2013) and approved by the Bioethics Committee of the University of Salamanca. 161 Schools, nursing homes, and early care centers providing support to children with IDD were 162 contacted for data collection. Those interested in collaborating were sent more detailed

163

164

165

166

167

168

169

170

171

172

173

174

175

176

177

178 information, and meetings were arranged to complete the SIS-C. Informed consent was signed by the parents or guardians of each participating child at the beginning of the study. Personal data were stored and protected, guaranteeing the confidentiality and anonymity of the participants. The collaboration in this study was voluntary and free of charge.

The SIS-C was administered in pencil-and-paper format by a trained interviewer. In our research, about 70 interviewers, mainly psychologists, were trained to complete the scales. Based on our field notes, additional guidance was provided to them when the support needs of children with greater physical and communicative limitations were estimated, following the recommendations of Schalock et al. (2018, p. 26). Once data collection ended, reports were returned, along with a certificate of participation. Telephone and email communication were constant between participants and the research team.

\section{Data Analysis}

\section{Missing data}

Fourteen cases $(1.5 \%)$ showed some missing data. Given the low prevalence and the fact that the coverage variable was higher than $99 \%$ in all cases, we used pairwise deletion to handle missing data.

\section{Specification of the SIS-C measurement model}

According to Seo et al. (2016) and Verdugo et al. (2019), we specified the SIS-C model from a multitrait-multimethod (MTMM) approach, in which support needs indicators were measured by seven support needs factors (corresponding to the seven domains) and three method factors (type, frequency, and time). Given several traits measured by different methods, the MTMM 
184 framework (Campbell \& Fiske, 1959) allows for the assessment of convergent validity (i.e., that

185

186

187

188

189

190

191

192

193

194

195

196

197

198

199

200

201

202

203

204

205

206

207

208

209

210

211

212

213

214

215

216

217

218

219

220

221

222

different assessment methods have concurrent validity in measuring the same construct) and discriminant validity (i.e., the degree to which different constructs measured with the same method are empirically separable). The MTMM approach has been integrated into confirmatory factor analysis (Jöreskeg, 1971; Marsh \& Hocevar, 1988; Widaman, 1985) through the development of nested model taxonomies. Its usage is recommended when the measurement method is expected to affect the indicators under evaluation. In the case of the SIS-C, the effects of the method on support needs indicators reach 12\% (Aguayo et al., 2019), so its incorporation to the model is necessary to obtain unbiased estimates on the latent variables of interest.

We grouped indicators (i.e., items) of each factor in parcels due to the complex parameterization of the SIS-C model (where a complete estimation of the raw data would result in a model with more than 1,000 parameters). The problem with over-parameterized models is how they tend to get a poor fit due to the cumulative effect of small errors of specification; in these cases, it is justified to reduce the number of parameters by creating parcels (Marsh et al., 2014; Morin et al., 2016). We formed three parcels for each support factor, after verifying their correct functioning according to the recommendations of Little et al. (2002). Each parcel was composed of the sum of the item scores for each measurement method (type, frequency, and time), following the instructions in the SIS-C manual for obtaining direct scores. Thus, Parcel 1 of each factor is the sum of the item scores considering the type of support, Parcel 2 is the sum of the scores to the frequency of support, and Parcel 3 is the sum of the scores given to daily support time.

The measurement model was specified, as shown in Figure 1. The support needs factors comprised the sum of the scores of three parcels (e.g., the "Home" factor is measured by Parcels 1,2 , and 3 of that support factor). The method factors summed the parcels that referred to that method (e.g., the "Type of support" factor is measured by the Parcels 1 of all support factors). Correlations were also specified between the seven factors of support needs and between the three methods.

The model was estimated using robust maximum likelihood (MLR). The model fit was evaluated by considering the usual recommendations (Browne \& Cudeck, 1992; Hu \& Bentler, 1999): comparative fit index (CFI) and Tucker-Lewis index (TLI) above .90 and .95 indicate a good fit, while a root mean square error of approximation (RMSEA) index below .08 indicates an acceptable fit. The local fit was evaluated by examining the modification indices (MI) in combination with the standardized expected parameters of change (SEPC). Significant MI values combined with SEPC values above .20 suggest the presence of possible relevant errors of specification (Saris et al., 2009).

\section{Classification of individuals according to their medical and behavioral needs}

The SIS-C manual recommends adding up the scores on the medical and behavioral needs items to obtain estimates of their intensity. However, we decided not to use the raw sum of scores since it is doubtful that items that refer to conditions of different severity (e.g., tube feeding and turning) will load similarly in the estimation of the needs. Instead, we used a formative model of

Peer) reviewing PDF | (2020:03:47138:1:0:NEW 18 Jun 2020) 
223

224

225

226

227

228

229

230

231

232

233

234

235

236

237

238

239

240

241

242

243

244

245

246

247

248

249

250

251

252

253

254

255

256

257

258

259

260

measurement in which exceptional needs items were predictive of a principal component (Borsboom, 2006; Preacher \& MacCallum, 2003). The resulting component was a weighted sum score that more accurately estimates the overall severity than unweighted sums of raw scores. Once the weighted scores were obtained, four groups were formed for each set of medical or behavioral needs: Group 1 (G1; no exceptional needs) included children who scored zero, and other groups included the remaining scores. Given the high positive asymmetry obtained, we classified in Group 2 (G2; low needs) the children with scores between the lowest fence and the median, in Group 3 (G3; moderate needs) the children with scores between the median and the upper quartile, and in Group 4 (G4; high needs) the children with scores between the upper quartile and the upper fence.

\section{Comparison between groups}

Once a well-fitting measurement model of the SIS-C was obtained, we estimated the factorial scores of support needs (expected a posteriori method) and the weighted scores in the exceptional needs' components. From these scores, we estimated the differences in support needs between the four groups (G1, G2, G3, and G4) by t-tests for the difference of means. For its interpretation, we inspected the statistical significance, effect size, and factor score distributions in each group. Likewise, for a visual representation of the results, we elaborated figures with the factorial means and the confidence intervals (95\%), following the recommendation of Cumming and Finch (2005).

\section{Results}

\section{Specification of the SIS-C measurement model}

The MTMM model had an acceptable fit at RMSEA (.061, CI= .056-.066) and a good fit at CFI (.98), TLI (.97), and SRMR (.01). The method factors captured $12 \%$ of the common variance, with the remainder $(88 \%)$ assumed by the support needs factors. Moreover, the support needs factors explained $76.5 \%$ of the total variance of the data, indicating a good measurement quality. We then inspected the model modification rates, finding none extremely high to indicate any potential specification problems. Consequently, we decided not to introduce any modifications to the model.

\section{Classification of individuals according to their medical and behavioral needs}

First, we estimated the optimal number of components to be extracted in the medical and behavioral needs sets by parallel analysis (Horn, 1965) on polychoric correlation matrices with 1,000 permutations. In both sets, the analysis recommended retaining only one component, since the real data eigenvalues were lower than the average of the random eigenvalues from the second component onwards. Then, scores were estimated in each component, and the children were classified according to their level of exceptional needs. In terms of medical needs, $47.3 \%$ were classified in G1 (no needs), 27\% in G2 (low needs), 13.4\% in G3 (moderate needs), and 12.3\% in G4 (high needs). In behavioral needs, 35.3\% were classified in G1, 30\% in G2, 20\% in G3, and $14.7 \%$ in $\mathrm{G} 4$. 


\section{Exceptional medical needs}

262 Once the children were grouped according to the intensity of their medical needs, comparisons 263 were made. Table 2 shows the results of t-tests for the difference of means, and Figure 2

264 represents them in graphical format. We found significant differences $(p<.05)$ among the four 265 intensity groups in the seven support needs factors. The effect sizes ranged from 1.99 found in 266 the Home factor between G1 and G4, to 0.28, in the Community factor between G3 and G4. 267 Eventually following this pattern, the largest differences appeared for all support needs factors 268 between G1 and G4 (large effect sizes, ranging from 1.09 to 1.99) and the smallest differences 269 between G3 and G4 (small-medium effect sizes, ranging from 0.28 to 0.44 ). The distribution of 270 groups suggested an asymptotic curve so that at lower intensities of support needs, there was a 271 greater growth between groups than at higher intensities of support needs. This finding indicates 272 that at a certain point (i.e., when medical needs are high), there was no relevant change in the 273 profile of support needs in any area of daily living.

274 The higher the need for medical support, the greater the intensity of support needs. In fact, the 275 increase between G1 (no needs) and G2 (low needs) was greater than 0.5 points, and the 276 differences tended to be homogeneous in greater support needs. However, there were differences 277 between the seven support needs factors. The largest differences among the groups were found in 278 the Home and School participation factors, where the means differed by almost 1.5 points from 279 each other, and effect sizes ranged from 0.451 .99 to 0.341 .5 , respectively. Although the 280 smallest differences were found in School learning (effect sizes between 0.33 and 1.08), the 281 other support factors obtained similar values to this one.

282 The differences between the groups can be explored by looking at the error bars in the figures. 283 The dispersion of scores was the most homogeneous in G4 of all the support needs factors, 284 which is indicative of greater homogeneity in this group of needs. Likewise, the groups seemed 285 more homogeneous in School learning and Health and safety.

\section{Exceptional behavioral needs}

287 The differences between groups of behavioral needs (Figure 3) showed a different pattern than 288 that of the medical needs. First, all scores were found to be within one standard deviation (as 289 opposed to almost two standard deviations in medical needs), suggesting less dispersion of 290 scores and, therefore, less difference between the groups. Second, although significant 291 differences were found in all support needs factors between G1, G3, and G4, this was not the 292 case in the other comparisons. The differences between G1 and G2 were significant $(p<.05)$ in all 293 factors except Health and Advocacy; the differences between G2 and G4 were significant in all 294 cases; and the differences between G3 and G4 were significant in all cases except Home. 295 However, the differences between G2 and G3 were significant only in Health, Social, and 296 Advocacy. This result suggests that while the impact of behavioral support needs was 297 progressive across intensity groups, there were fewer differences between medium intensity 298 groups (i.e., G2 and G3). 
299 Considering the support needs factors, those with the widest range were Social and School 300 participation and that with the most homogeneity of scores was School learning. The largest 301 effect sizes were found in Social (range 0.27 to 0.83 ) and School participation (range 0.13 to 302 0.61), and the smallest in School learning (range 0.07 to 0.49) and Home (range 0.09 to 0.42).

\section{Discussion}

304 The present study

305 In this study, we compared four intensity groups of medical and behavioral needs to explore their 306 influence on overall support needs in a sample of children with IDD. The results showed that 307 medical conditions and challenging behaviors might cause extra support needs beyond the 308 intensity of support needs in children with disabilities measured in the SIS-C. Differences were 309 found in both medical and behavioral needs, suggesting their relevant effect on support needs.

310 For medical needs, analysis of the data gathered showed statistically significant differences in 311 support needs among the groups in all seven support domains (as medical needs increased in 312 intensity, so did the assessed support needs). The highest differences, as would be expected, were 313 in comparisons between the G1 and G4 groups; the smallest (but still statistically significant) in 314 the G3 and G4 comparisons. Effect sizes were generally consistent across domains, although the 315 effect sizes in School learning domain comparisons were smaller than in the other domains. The 316 finding that smaller differences were found in the domain of School learning might be explained 317 by considering that most of the participants attended special education schools and, therefore, 318 received the common support of this educational context. Differences in the intensity of support 319 needed for School learning may not be as accurately reflected in comparison with other domains, 320 including School participation, where the support needs of students with intellectual disabilities 321 are less dependent on the context than on the presence of special health care needs.

322 The impact of medical needs was non-linear but showed an increase in low levels of intensity 323 (i.e., no needs, low needs) that tended to homogenize at higher levels (i.e., moderate and high 324 needs). In turn, we found significant differences between having no needs and having any degree 325 of needs, suggesting that medical needs have a considerable effect on the support needs of a child with IDD. This result is consistent with other studies, which conclude that the profile of support needs of individuals with severe and profound disabilities is different from those with mild impairments (van Timmeren et al., 2017). Support needs are maximal with severe disabilities, so there is little difference between moderate and high levels of needs. This result depicts the expected increase in support needs given additional health problems, which is characteristic when several functional limitations occur together.

We found that the difference between having no behavioral needs and having high needs is significant $(p<.05)$ in all areas. However, the influence of low-medium levels of needs appears to 335 be dependent on the situation since it was significant only in some support domains. Thus, we identified that the greatest impact of behavioral needs was in the areas of Social and School 
336 participation, in which the relationship with peers is also the most common behavioral difficulty 337 among children with higher impairments (Parkes et al., 2008; van Gorp et al., 2019).

338 The different impact of medical and behavioral needs has been shown in other research, where 339 the medical needs were more related to support needs than behavioral ones (Bertoncelli et al., 340 2019). In turn, Smit et al. (2011) suggested that the lower influence of behavioral needs could be 341 attributed to the fact that the SIS's set of behaviors is mostly externalizing (e.g., aggression 342 towards others) and, therefore, does not seem likely to be carried out by people with motor 343 impairments. Arnkelsson and Sigurdsson (2016) found negative effects of the set of behavioral

344

345

346

347

348

349

350

351

352

353

354

355

356

357

358

359

360

361

362

363

364

365

366

367

368

369

370

371

372

373

374 needs on overall support needs, which they attributed to an anomaly in the data. Seo et al. (2017) found that young adults with higher medical and behavioral needs had higher support needs, except in the areas of Community and Health, where there were no significant differences with the group of high medical needs but rather low behavioral needs. They concluded that having high medical needs had more influence on those domains of support.

The stability of the need for support in persons with disabilities might explain our results. While medical support needs remain constant over time, behavioral needs are situational. Therefore, the difference between no behavioral needs and high needs is significant; however, at low and moderate levels, there is no impact on overall support needs, perhaps because some form of intermittent support should be provided anyway. Conversely, the intensity of medical needs increases enormously at low and moderate levels; however, it is no longer significant at high and very high levels of needs, where support is arranged on a permanent and ongoing basis. These results expose differences in medical and behavioral support planning that may be relevant to service eligibility and resource allocation (Agosta et al., 2016; Fortune et al., 2009). We also underpin that the problematic identification of behavioral or emotional problems in people with higher levels of support needs (Bjorgaas et al., 2012) might require sensitive items at all levels of intensity of support needs.

\section{Limitations}

This study has some limitations that must be considered. Firstly, due to the sample size, we could not perform the analyses differentiating the results by health conditions (e.g., cerebral palsy or autism), as the variability within the groups was very small and did not allow us to obtain reliable analyses. While the type of health condition should not be relevant to a support needs assessment, which is primarily concerned with the individual's levels of functioning, considering different IDD may help to explore the effects of mobility or social behavior on the pattern of medical needs (as in the study on physical disability by Smit et al., 2011) or behavioral needs (as in the study on children with autism by Shogren et al., 2017).

Second, we did not analyze the contextual variables that could help us understand the support profile of the children assessed. An assessment of support needs should consider environmental aspects that may influence the support needs profile. In this sense, a study on access to health services or the possibility of participating in different activities in school would have been relevant. 
375 Finally, a limitation of our study is that we did not use any other tool than SIS-C to collect data

376 on such needs (medical and behavioral). For instance, we consider pain to be an important

377 problem affecting the well-being of children with greater limitations and their performance in

378 activities (Horwood et al., 2019; Parkes et al., 2008). Likewise, communication problems among

379 children with greater limitations is a mediator in social and participation areas (Caynes et al.,

380 2019), so it also may influence the need for support. Our results can only be interpreted by

381 considering the SIS-C's sets of needs.

\section{Implications for practice and future research}

383 The main implication of classifying individuals according to their support needs is resource

384

385

386

387

388

389

390

391

392

393

394

395

396

397

398

399

400

401

402

403

404

405

406

407

408

409

410

411

allocation and the identification of common support strategies among individuals with a similar level of needs. Support needs data also serves to select the priority areas of intervention. In this study, we found that the greatest need for medical and behavioral support principally influence the domains of Home, School Participation, and Social, being possibly the areas where more agents are involved, whether they are family, teachers, or peers and friends. Therefore, we join other authors' initiatives to propose support strategies for individuals with more significant needs, such as an improvement of the relationship with medical services, a family-centered care model, better opportunities for participation, along with enhancement of social inclusion and communication with peers (Anaby et al., 2019; Ballard \& Dymond, 2018; Finnerty et al., 2019; Wehmeyer et al., 2016).

Nevertheless, classifications based on support needs may be complicated by a lack of terminology to refer to children with significant support needs. In this regard, a standardized scale such as the SIS-C can be used. In our study, higher support needs have been characterized by a combination of medical and behavioral support needs affecting all areas of daily life. The SIS-C appears appropriate for assessing support needs, but further research is urged to address the evaluation of children with greater support needs.

\section{Conclusions}

When there is a discrepancy between the personal competence and demands of the environment, support needs arise and guide the identification and provision of the best support strategies. We investigated the effect that medical and behavioral needs had on the support needs of children with IDD. Knowledge of the support needs of children is useful in informing work teams about priority areas that may be affecting the quality of their lives (Petry et al., 2007; Schalock, 2018; Verdugo, 2018). For guiding support planning, the usage of standardized tools for support needs measurement has been recommended.

\section{Acknowledgements}

We are thankful for the effort and time of professionals and families who have voluntarily collaborated and participated in the present study. 


\section{References}

413 Agosta, J., Petner-Arrey, J., Karedell, Y., Vazquez, A., Rojas, R., Taylor, B., \& Villwok, M.

414

415

416

417

418

419

420

421

422

423

424

425

426

427

428

429

430

431

432

433

434

435

436

437

438

439

440

441

442

443

444

445

446

447

448

449

450

451 (2016). Building personal supports budgets for adults with intellectual/developmental disabilities. Human Research Institute. https://ddsd.vermont.gov/sites/ddsd/files/documents/HSRIBuilding_Personal_Supports_Budgets-SIS_and_Assessment_Levels.pdf

Aguayo, V., Arias, V. B., Verdugo, M. Á., \& Amor, A. M. (2019). Measuring support needs in children with motor disability: Validity and utility of the Supports Intensity Scale (SIS-C). Research in Developmental Disabilities, 95, 1-11. https://doi.org/10.1016/j.ridd.2019.103509

American Association on Intellectual and Developmental Disabilities. (n.d.). International SIS Use. https://aaidd.org/sis/international\#.Wk6ZC9_iaUk

Anaby, D. R., Campbell, W. N., Missiuna, C., Shaw, S. R., Bennett, S., Khan, S., Tremblay, S., Kalubi-Lukusa, J., \& Camden, C. (2019). Recommended practices to organize and deliver school-based services for children with disabilities: A scoping review. Child: Care, Health and Development, 45(1), 15-27. https://doi.org/10.1111/cch.12621

Arnkelsson, G., \& Sigurdsson, T. (2016). The validity of the Supports Intensity Scale for adults with motor disability. American Journal on Intellectual and Developmental Disabilities, 121(2), 139-150. https://doi.org/10.1352/1944-7558-121.2.139

Ballard, S. L., \& Dymond, S. K. (2018). Inclusive education for secondary age students with severe disabilities and complex health care needs. Intellectual and Developmental Disabilities, 56(6), 427-441. https://doi.org/10.1352/1934-9556-56.6.427

Bertoncelli, C. M., Altamura, P., Vieira, E. R., Bertoncelli, D., Thummler, S., \& Solla, F. (2019). Identifying factors associated with severe intellectual disabilities in teenagers with cerebral palsy using a predictive learning model. Journal of Child Neurology, 34(4), 221-229. https://doi.org/10.1177/0883073818822358

Bjorgaas, H. M., Hysing, M., \& Elgen, I. (2012). Psychiatric disorders among children with cerebral palsy at school starting age. Research in Developmental Disabilities, 33(4), 1287 1293. https://doi.org/10.1016/j.ridd.2012.02.024

Borsboom, D. (2006). The attack of the psychometricians. Psychometrika, 71(3), 425-440. https://doi.org/10.1007/s11336-006-1447-6

Browne, M. W., \& Cudeck, R. (1992). Alternative ways of assessing model fit. Sociological Methods \& Research, 21(2), 230-258. https://doi.org/10.1177/0049124192021002005

Campbell, D. T., \& Fiske, D. W. (1959). Convergent and discriminant validation by the multitrait-multimethod matrix. Psychological Bulletin, 56(2), 81-105. https://doi.org/10.1037/h0046016

Caynes, K., Rose, T. A., Theodoros, D., Burmester, D., Ware, R. S., \& Johnston, L. M. (2019). The Functional Communication Classification System: extended reliability and concurrent validity for children with cerebral palsy aged 5 to 18 years. Developmental Medicine \& Child Neurology, 61(7), 805-812. https://doi.org/10.1111/dmcn.14135 
452 Chou, Y.-C., Lee, Y.-C., Chang, S.-C., \& Yu, A. P.-L. (2013). Evaluating the Supports Intensity

453

454

455

456

457

458

459

460

461

462

463

464

465

466

467

468

469

470

471

472

473

474

475

476

477

478

479

480

481

482

483

484

485

486

487

488

489

490
Scale as a potential assessment instrument for resource allocation for persons with intellectual disability. Research in Developmental Disabilities, 34(6), 2056-2063. https://doi.org/10.1016/j.ridd.2013.03.013

Cumming, G., \& Finch, S. (2005). Inference by eye: Confidence intervals and how to read pictures of data. American Psychologist, 60(2), 170-180. https://doi.org/10.1037/0003066X.60.2.170

Finnerty, M. S., Jackson, L. B., \& Ostergren, R. (2019). Adaptations in general education classrooms for students with severe disabilities: Access, progress assessment, and sustained use. Research and Practice for Persons with Severe Disabilities, 44(2), 87-102. https://doi.org/10.1177/1540796919846424

Fortune, J., Agosta, J., Auerbach, K., Kimmich, M., Melda, K., Smith, D., Taub, S., \& Burns, P. (2009). Developing reimbursement levels using the Supports Intensity Scale (SIS) in Louisiana. Human Services Research Institute.

Giné, C., Font, J., Adam-Alcocer, A. L., Alomar, E., Dalmau, M., Simó-Pinatella, D., BalcellsBalcells, A., Mas, J. M., Baqués, N., Carbó-Carreté, M., Salvador-Bertrán, F., Oliveira, C., \& Gonzalez-Raventós, M. (2017). Escala d'Intensitat dels Suports per a infants $i$ adolescents (EIS-I/A). Manual per a l'ús/administració [Supports Intensity Scale for children and adolescents (SIS-C/A). User administration manual]. Universitat Ramon Llull. http://recerca.blanquerna.edu/discapacitat-qualitat-vida/wpcontent/uploads/2018/03/Manual-EIS-I-A-2017.pdf

Giné, C., Font, J., Guàrdia-Olmos, J., Balcells-Balcells, A., Valls, J., \& Carbó-Carreté, M. (2014). Using the SIS to better align the funding of residential services to assessed support needs. Research in Developmental Disabilities, 35(5), 1144-1151. https://doi.org/10.1016/j.ridd.2014.01.028

Horn, J. L. (1965). A rationale and test for the number of factors in factor analysis. Psychometrika, 30(2), 179-185. https://doi.org/10.1007/BF02289447

Horwood, L., Li, P., Mok, E., Oskoui, M., Shevell, M., \& Constantin, E. (2019). Behavioral difficulties, sleep problems, and nighttime pain in children with cerebral palsy. Research in Developmental Disabilities, 95, 1-9. https://doi.org/10.1016/j.ridd.2019.103500

Hu, L., \& Bentler, P. M. (1999). Cutoff criteria for fit indexes in covariance structure analysis: Conventional criteria versus new alternatives. Structural Equation Modeling: A Multidisciplinary Journal, 6(1), 1-55. https://doi.org/10.1080/10705519909540118

Jöreskeg, K. G. (1971). Statistical analysis of sets of congeneric tests. Psychometrika, 36(2), 109-133.

Kyzar, K. B., Turnbull, A. P., Summers, J. A., \& Gómez, V. A. (2012). The relationship of family support to family outcomes: A synthesis of key findings from research on severe disability. Research and Practice for Persons with Severe Disabilities, 37(1), 31-44. https://doi.org/10.2511/027494812800903247 
491

492

493

494

495

496

497

498

499

500

501

502

503

504

505

506

507

508

509

510

511

512

513

514

515

516

517

518

519

520

521

522

523

524

525

526

527

528

Little, T. D., Cunningham, W. A., Shahar, G., \& Widaman, K. F. (2002). To parcel or not to parcel: Exploring the question, weighing the merits. Structural Equation Modeling: A Multidisciplinary Journal, 9(2), 151-173. https://doi.org/10.1207/S15328007SEM0902_1

Lombardi, M., Croce, L., Claes, C., Vandevelde, S., \& Schalock, R. L. (2016). Factors predicting quality of life for people with intellectual disability: Results from the ANFFAS study in Italy. Journal of Intellectual \& Developmental Disability, 41(4), 338-347. https://doi.org/10.3109/13668250.2016.1223281

Marsh, H. W., \& Hocevar, D. (1988). A new, more powerful approach to multitrait-multimethod analyses: Application of second-order confirmatory factor analysis. Journal of Applied Psychology, 73(1), 107-117. https://doi.org/10.1037/0021-9010.73.1.107

Marsh, H. W., Morin, A. J. S., Parker, P. D., \& Kaur, G. (2014). Exploratory structural equation modeling: An integration of the best features of exploratory and confirmatory factor analysis. Annual Review of Clinical Psychology, 10(1), 85-110. https://doi.org/10.1146/annurev-clinpsy-032813-153700

Mazza, M. G., Rossetti, A., Crespi, G., \& Clerici, M. (2019). Prevalence of co-occurring psychiatric disorders in adults and adolescents with intellectual disability: A systematic review and meta-analysis. Journal of Applied Research in Intellectual Disabilities, Advance online publication. https://doi.org/10.1111/jar.12654

Morin, A. J. S., Arens, A. K., \& Marsh, H. W. (2016). A bifactor exploratory structural equation modeling framework for the identification of distinct sources of construct-relevant psychometric multidimensionality. Structural Equation Modeling: A Multidisciplinary Journal, 23(1), 116-139. https://doi.org/10.1080/10705511.2014.961800

Nakken, H., \& Vlaskamp, C. (2007). A need for a taxonomy for profound intellectual and multiple disabilities. Journal of Policy and Practice in Intellectual Disabilities, 4(2), 8387. https://doi.org/10.1111/j.1741-1130.2007.00104.x

Parkes, J., White-Koning, M., Dickinson, H. O., Thyen, U., Arnaud, C., Beckung, E., Fauconnier, J., Marcelli, M., McManus, V., Michelsen, S. I., Parkinson, K., \& Colver, A. (2008). Psychological problems in children with cerebral palsy: A cross-sectional European study. Journal of Child Psychology and Psychiatry, 49(4), 405-413. https://doi.org/10.1111/j.1469-7610.2007.01845.x

Petitpierre, G., Wolf, D., Dietrich, A., Benz, M., \& Adler, J. (2007). Integration of education and care given to children with profound multiple disabilities in Switzerland. Journal of Policy and Practice in Intellectual Disabilities, 4(2), 141-151. https://doi.org/10.1111/j.17411130.2007.00111.x

Petry, K., Maes, B., \& Vlaskamp, C. (2007). Support characteristics associated with the quality of life of people with profound intellectual and multiple disabilities: The perspective of parents and direct support staff. Journal of Policy and Practice in Intellectual Disabilities, 4(2), 104-110. https://doi.org/10.1111/j.1741-1130.2007.00107.x

Peer) reviewing PDF | (2020:03:47138:1:0:NEW 18 Jun 2020) 
529 Preacher, K. J., \& MacCallum, R. C. (2003). Repairing Tom Swift's electric factor analysis

530

531

532

533

534

535

536

537

538

539

540

541

542

543

544

545

546

547

548

549

550

551

552

553

554

555

556

557

558

559

560

561

562

563

564

565

566

567 machine. Understanding Statistics, 2(1), 13-43. https://doi.org/10.1207/S15328031US0201_02

Saris, W. E., Satorra, A., \& van der Veld, W. M. (2009). Testing structural equation models or detection of misspecifications? Structural Equation Modeling: A Multidisciplinary Journal, 16(4), 561-582. https://doi.org/10.1080/10705510903203433

Schalock, R. L. (2018). Six ideas that are changing the IDD field internationally. Siglo Cero, 49(1), 21-33. https://doi.org/10.14201/scero20184912133

Schalock, R. L., Borthwick-Duffy, S. A., Bradley, V. J., Buntinx, W. H. E., Coulter, D. L., Craig, E. M., Gomez, S. C., Lachapelle, Y., Luckasson, R., Reeve, A., Shogren, K. A., Snell, M. E., Spreat, S., Tassé, M. J., Thompson, J. R., Verdugo, M. A., Wehmeyer, M. L., \& Yeager, M. H. (2010). Intellectual disability: Definition, classification, and systems of supports (11th ed.). American Association on Intellectual and Developmental Disabilities.

Schalock, R. L., Thompson, J. R., \& Tassé, M. J. (2018). How organizations and systems use Supports Intensity Scales [White paper]. American Association on Intellectual and Developmental Disabilities. https://aaidd.org/docs/default-source/sisdocs/howorganizationsusesis_webrev-final.pdf?sfvrsn=d4953021_0

Seo, H., Shogren, K. A., Little, T. D., Thompson, J. R., \& Wehmeyer, M. L. (2016). Construct validation of the Supports Intensity Scale - Children and Adult versions: An application of a pseudo multitrait-multimethod approach. American Journal on Intellectual and Developmental Disabilities, 121(6), 550-563. https://doi.org/10.1352/1944-7558121.6.550

Seo, H., Shogren, K. A., Wehmeyer, M. L., Little, T. D., \& Palmer, S. B. (2017). The impact of medical/behavioral support needs on the supports needed by adolescents with intellectual disability to participate in community life. American Journal on Intellectual and Developmental Disabilities, 122(2), 173-191. https://doi.org/10.1352/1944-7558122.2.173

Shogren, K. A., Wehmeyer, M. L., Seo, H., Thompson, J. R., Schalock, R. L., Hughes, C., Little, T. D., \& Palmer, S. B. (2017). Examining the reliability and validity of the Supports Intensity Scale-Children's version in children with autism and intellectual disability. Focus on Autism and Other Developmental Disabilities, 32(4), 293-304. https://doi.org/10.1177/1088357615625060

Smit, W., Sabbe, B., \& Prinzie, P. (2011). Reliability and validity of the Supports Intensity Scale (SIS) measured in adults with physical disabilities. Journal of Developmental and Physical Disabilities, 23(4), 277-287. https://doi.org/10.1007/s10882-011-9227-3

Thompson, J. R., Bradley, V. J., Buntinx, W. H. E., Schalock, R. L., Shogren, K. A., Snell, M. E., Wehmeyer, M. L., Borthwick-Duffy, S., Coulter, D. L., Craig, E. M., Gomez, S. C., Lachapelle, Y., Luckasson, R. A., Reeve, A., Spreat, S., Tassé, M. J., Verdugo, M. A., \& Yeager, M. H. (2009). Conceptualizing supports and the support needs of people with 
568

569

570

571

572

573

574

575

576

577

578

579

580

581

582

583

584

585

586

587

588

589

590

591

592

593

594

595

596

597

598

599

600

601

602

603

604

605

606

intellectual disability. Intellectual and Developmental Disabilities, 47(2), 135-146. https://doi.org/10.1352/1934-9556-47.2.135

Thompson, J. R., Bryant, B., Campbell, E. M., Craig, E. M., Hughes, C., Rotholz, D. A., Schalock, R. L., Silverman, W., Tassé, M. J., \& Wehmeyer, M. L. (2004). Supports Intensity Scale (SIS). User's manual. American Association on Mental Retardation.

Thompson, J. R., Hughes, C., Schalock, R. L., Silverman, W., Tasse, M. J., Bryant, B., Craig, E. M., \& Campbell, E. M. (2002). Integrating supports in assessment and planning. Mental Retardation, 40(5), 390-405. https://doi.org/10.1352/0047-

6765(2002)040<0390:ISIAAP>2.0.CO;2

Thompson, J. R., Walker, V. L., Shogren, K. A., \& Wehmeyer, M. L. (2018). Expanding inclusive educational opportunities for students with the most significant cognitive disabilities through personalized supports. Intellectual and Developmental Disabilities, 56(6), 396-411. https://doi.org/10.1352/1934-9556-56.6.396

Thompson, J. R., Wehmeyer, M. L., Hughes, C., Shogren, K. A., Palmer, S. B., \& Seo, H. (2014). The Supports Intensity Scale-Children's version: Preliminary reliability and validity. Inclusion, 2(2), 140-149. https://doi.org/10.1352/2326-6988-2.2.140

Thompson, J. R., Wehmeyer, M. L., Hughes, C., Shogren, K. A., Seo, H., Little, T. D., Schalock, R. L., Realon, R. E., Copeland, S. R., Patton, J. R., Polloway, E. A., Shelden, D., Tanis, S., \& Tassé, M. J. (2016). Supports Intensity Scale-Children's version. User's manual. American Association on Intellectual and Developmental Disabilities.

van Gorp, M., E. Roebroeck, M., van Eck, M., M. Voorman, J., Twisk, J. W. R., J. Dallmeijer, A., \& van Wely, L. (2019). Childhood factors predict participation of young adults with cerebral palsy in domestic life and interpersonal relationships: a prospective cohort study. Disability and Rehabilitation, 1-10. https://doi.org/10.1080/09638288.2019.1585971

van Loon, J. H. M., Bonham, G. S., Peterson, D. D., Schalock, R. L., Claes, C., \& Decramer, A. E. M. (2013). The use of evidence-based outcomes in systems and organizations providing services and supports to persons with intellectual disability. Evaluation and Program Planning, 36(1), 80-87. https://doi.org/10.1016/j.evalprogplan.2012.08.002

van Timmeren, E. A., Waninge, A., van Schrojenstein Lantman-de, H. M. J., van der Putten, A. A. J., \& van der Schans, C. P. (2017). Patterns of multimorbidity in people with severe or profound intellectual and motor disabilities. Research in Developmental Disabilities, 67, 28-33. https://doi.org/10.1016/j.ridd.2017.05.002

Verdugo, M. A. (2018). Conceptos clave que explican los cambios en las discapacidades intelectuales y del desarrollo en España [Key concepts and principles that explain changes in the provision of supports for intellectual and developmental disabilities in Spain]. Siglo Cero, 49(1), 35. https://doi.org/10.14201/scero20184913552

Verdugo, M. A., Arias, B., Guillén, V. M., \& Vicente, E. (2014). La escala de intensidad de apoyos para niños y adolescentes (SIS-C) en el contexto español [Support Intensity Scale for Children (SIS-C) in the Spanish context]. Siglo Cero, 45(1), 24-40. 
607 Verdugo, M. A., Arias, V. B., \& Guillén, V. M. (2019). Are type, frequency, and daily time 608 equally valid estimators of support needs in children with intellectual disability? A 609 multitrait-multimethod analysis of the Supports Intensity Scale for children (SIS-C). 610 Assessment, 26(7), 1307-1319. https://doi.org/10.1177/1073191117732411

611 Verdugo, M. A., Guillén, V. M., Arias, B., Vicente, E., \& Badia, M. (2016). Confirmatory factor 612 analysis of the Supports Intensity Scale for children. Research in Developmental 613 Disabilities, 49-50, 140-152. https://doi.org/10.1016/j.ridd.2015.11.022

614 Walker, V. L., Loman, S. L., Hara, M., Park, K. L., \& Strickland-Cohen, M. K. (2018).

615 Examining the inclusion of students with severe disabilities in school-wide positive 616 behavioral interventions and supports. Research and Practice for Persons with Severe 617 Disabilities, 43(4), 223-238. https://doi.org/10.1177/1540796918779370

618 Wehmeyer, M. L., Shogren, K. A., Kurth, J. A., Morningstar, M. E., Kozleski, E. B., Agran, M., 619 Jackson, L., Jameson, J. M., McDonnell, J., \& Ryndak, D. L. (2016). Including students 620 with extensive and pervasive support needs. In J. P. Bakken \& F. E. Obiakor (Eds.), General and special education inclusion in an age of change: impact on students with disabilities (Advances in Special Education) (Vol. 31, pp. 129-155). Emerald Group Publishing Limited. https://doi.org/10.1108/S0270-401320160000031009

Widaman, K. F. (1985). Hierarchically nested covariance structure models for multitraitmultimethod data. Applied Psychological Measurement, 9(1), 1-26. https://doi.org/10.1177/014662168500900101

World Medical Association. (2013). World Medical Association Declaration of Helsinki. Journal of the American Medical Association, 310(20), 2191-2194. https://doi.org/10.1001/jama.2013.281053

Zijlstra, H. P., \& Vlaskamp, C. (2005). The impact of medical conditions on the support of children with profound intellectual and multiple disabilities. Journal of Applied Research in Intellectual Disabilities, 18(2), 151-161. https://doi.org/10.1111/j.14683148.2005.00244.x 
Figure 1

Representation of the measurement model of support needs.

The grey circles represent the seven factors of support needs, the white circles represent the three method factors, while the white squares represent the parcels (P). For clarity, the error terms of the parcels have not been represented. 


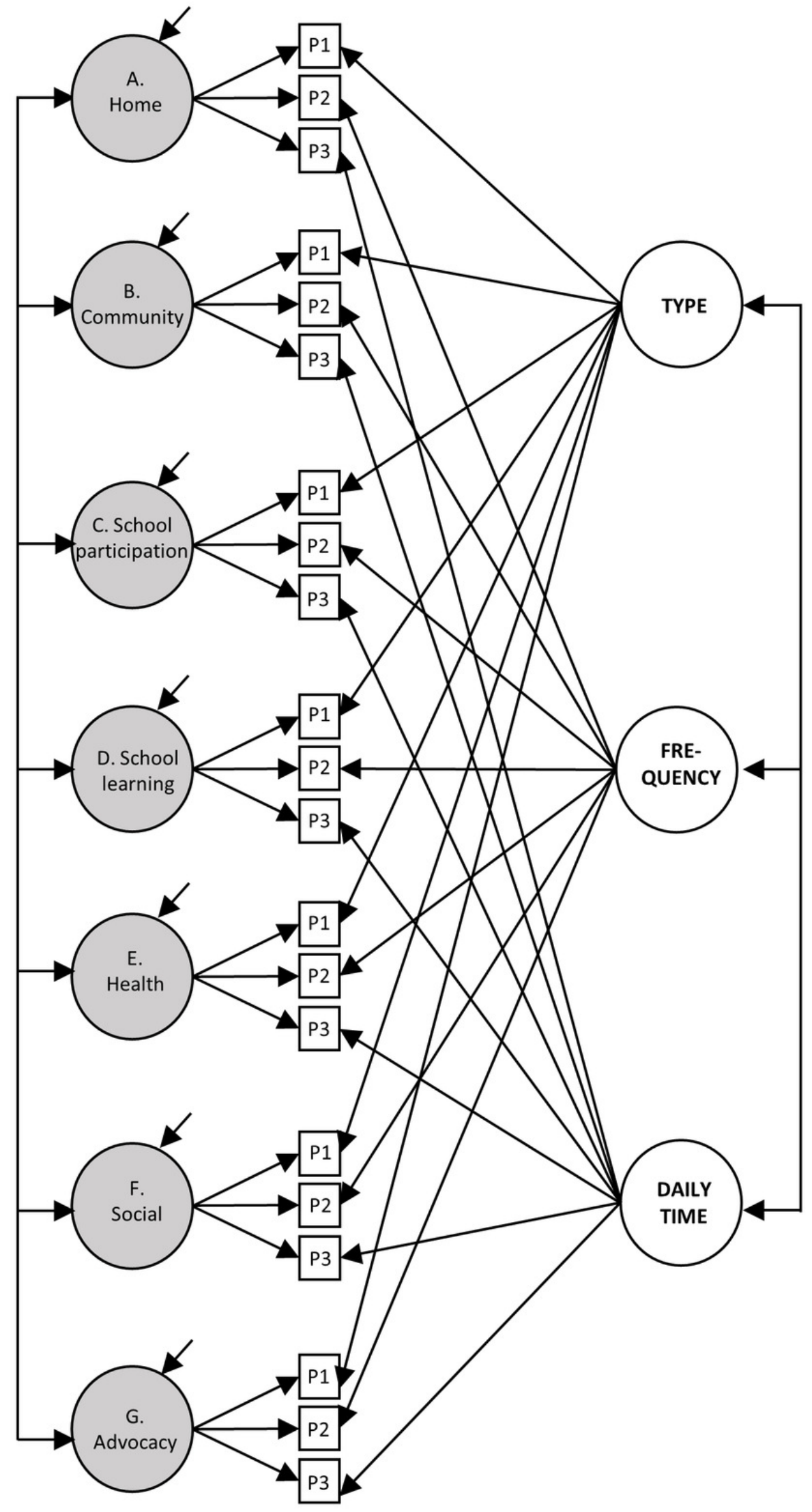


Figure 2

Distribution by support factors of the factorial means and the confidence intervals (95\%) of the four groups of medical needs.

$\mathrm{G} 1=$ no needs, $\mathrm{G} 2=$ low needs, $\mathrm{G} 3=$ moderate needs, and $\mathrm{G} 4=$ high needs

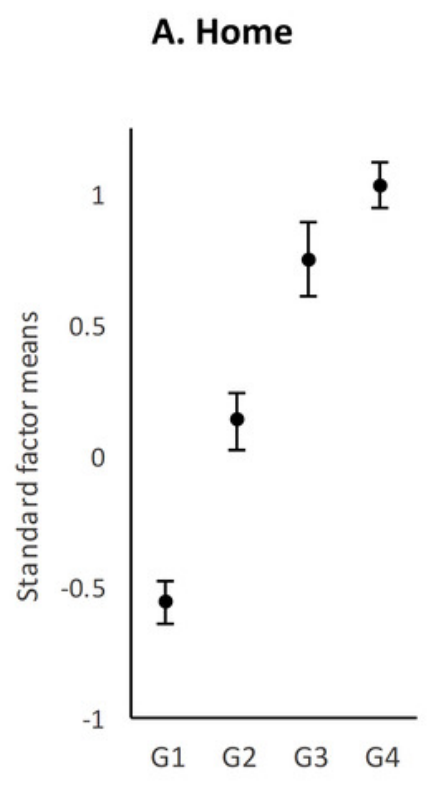

B. Community

C. School participation

D. School learning
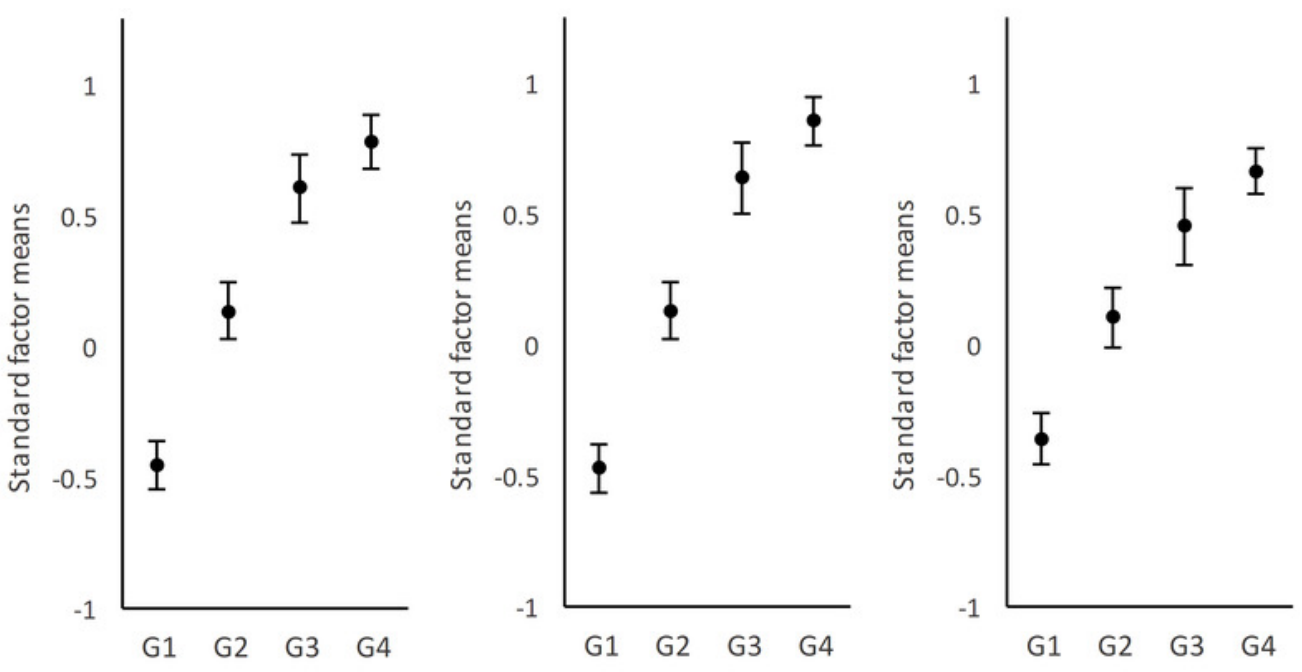

E. Health and safety

F. Social

G. Advocacy
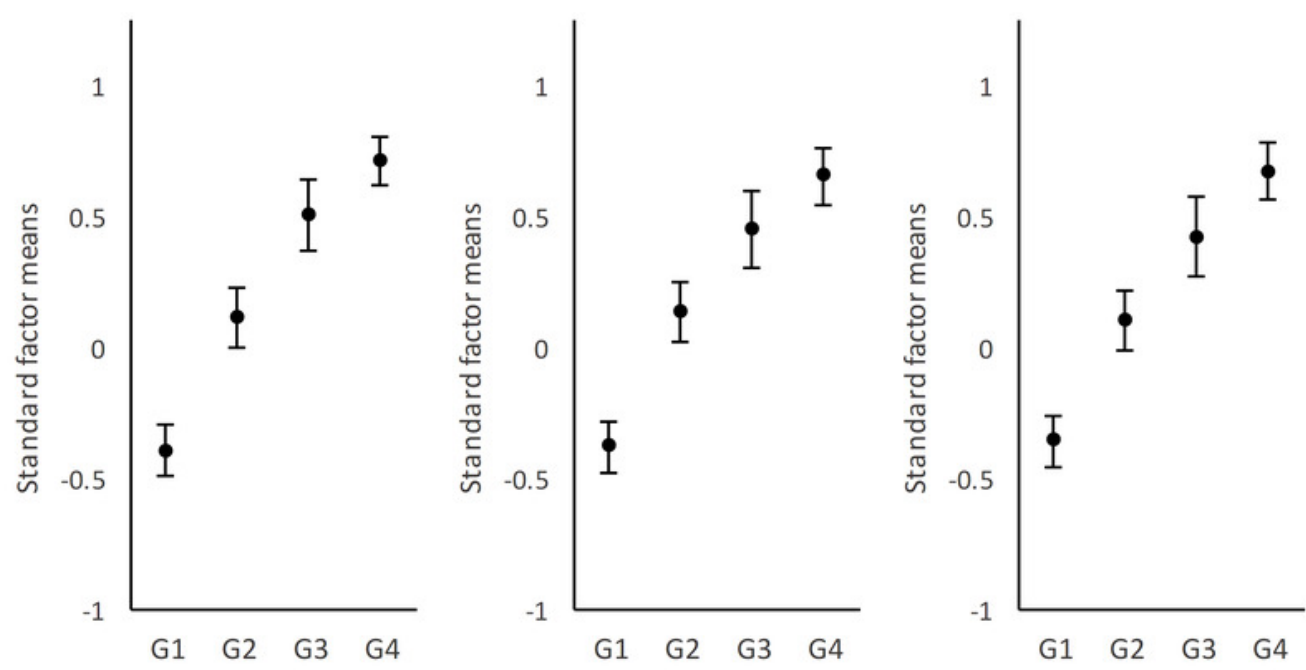
Figure 3

Distribution by support factors of the factorial means and the confidence intervals $(95 \%)$ of the four groups of behavioral needs.

$\mathrm{G} 1=$ no needs, $\mathrm{G} 2=$ low needs, $\mathrm{G} 3=$ moderate needs, and G4=high needs.
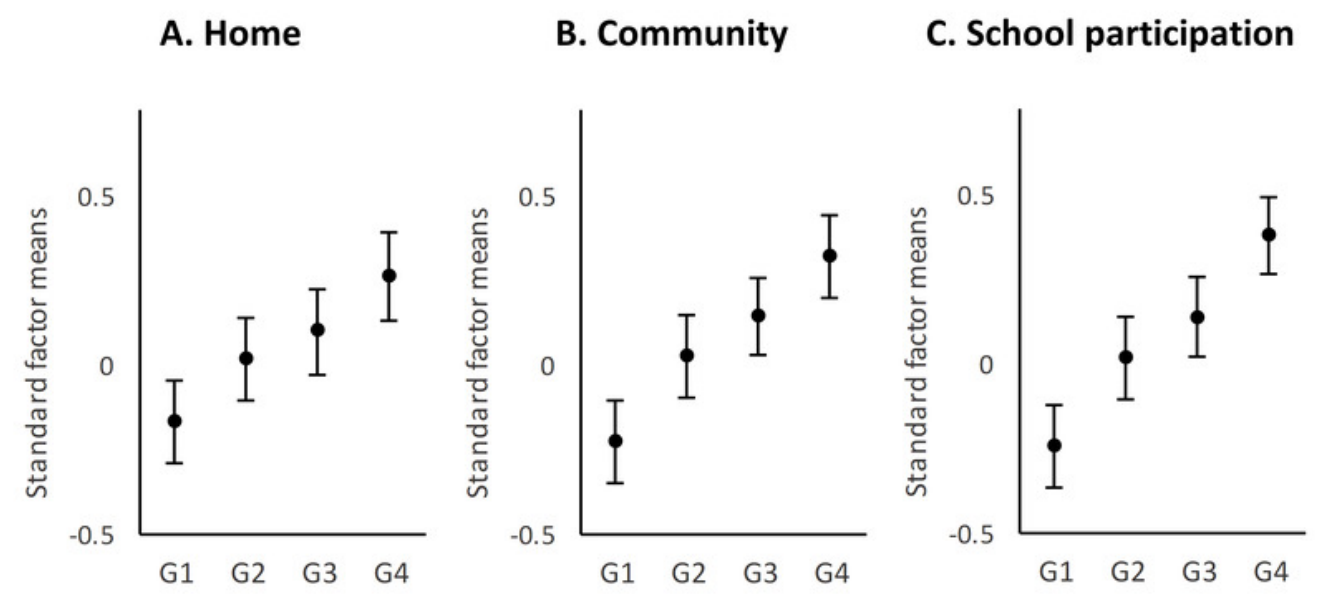

\section{School learning}

E. Health and safety

F. Social

G. Advocacy
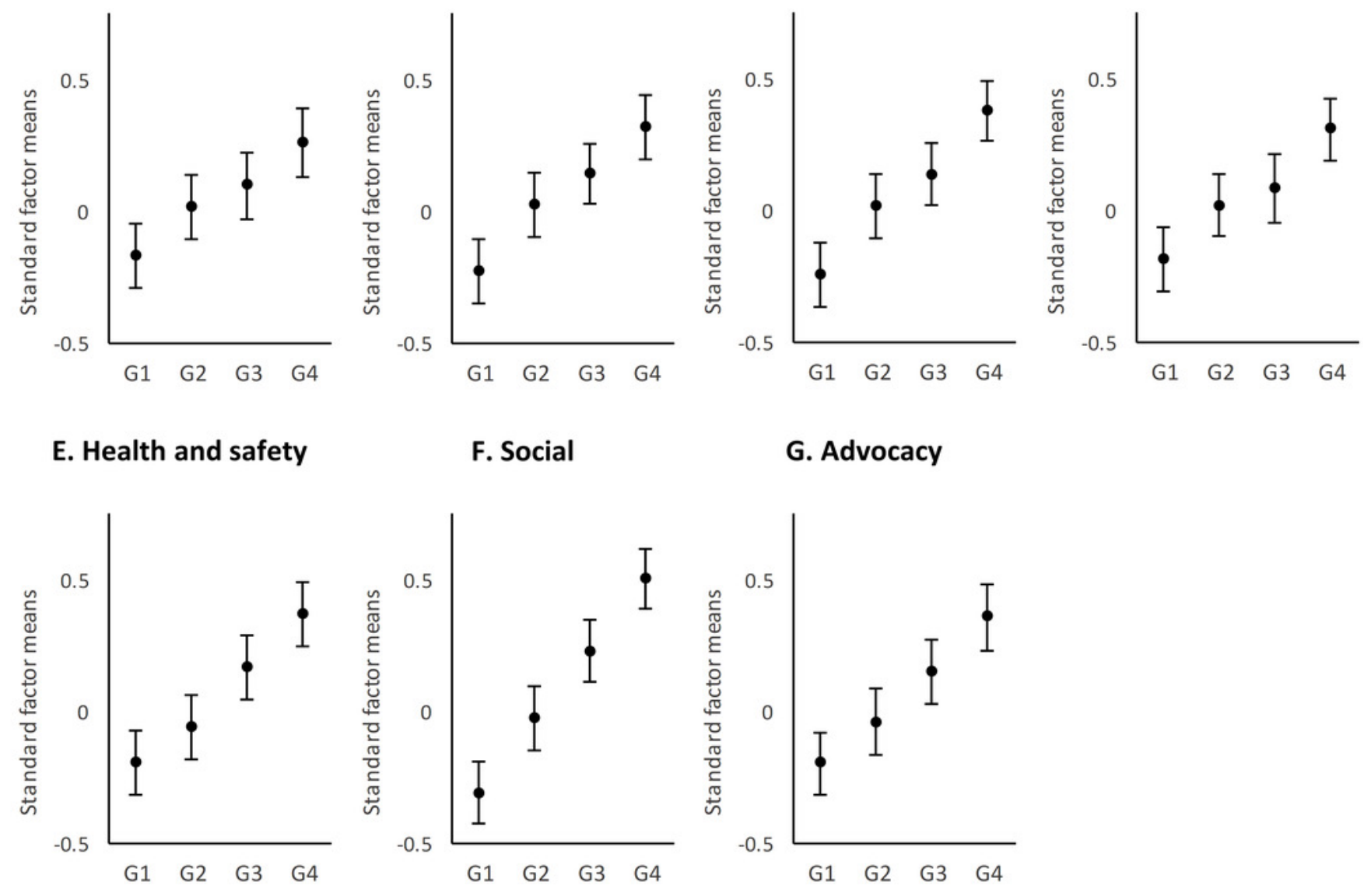


\section{Table 1 (on next page)}

Descriptive statistics for the children' characteristics $(n=911)$. 


\begin{tabular}{|c|c|}
\hline Variables & n $(\%)$ \\
\hline \multicolumn{2}{|l|}{ Gender } \\
\hline Male & $564(61.91 \%)$ \\
\hline Female & $347(38.09 \%)$ \\
\hline \multicolumn{2}{|l|}{ Age cohorts } \\
\hline $5-6$ & $121(13.28 \%)$ \\
\hline $7-8$ & $121(13.28 \%)$ \\
\hline $9-10$ & $119(13.06 \%)$ \\
\hline $11-12$ & $165(18.11 \%)$ \\
\hline $13-14$ & $214(23.49 \%)$ \\
\hline $15-16$ & $171(18.77 \%)$ \\
\hline \multicolumn{2}{|l|}{ Home setting } \\
\hline Family home & $868(95.28 \%)$ \\
\hline Others (residential homes, etc.) & $35(3.62 \%)$ \\
\hline Missing data & $10(1.10 \%)$ \\
\hline \multicolumn{2}{|l|}{ School setting } \\
\hline Ordinary school & $162(17.78 \%)$ \\
\hline Special classroom in ordinary school & $131(14.38 \%)$ \\
\hline Special education school & $612(67.18 \%)$ \\
\hline Missing data & $6(0.66 \%)$ \\
\hline \multicolumn{2}{|l|}{ Health condition } \\
\hline Intellectual disability & $403(44.24 \%)$ \\
\hline Intellectual disability and cerebral palsy & $135(14.82 \%)$ \\
\hline Intellectual disability and autism & $176(19.32 \%)$ \\
\hline Intellectual disability and sensory limitations & $40(4.38 \%)$ \\
\hline Intellectual disability, cerebral palsy and sensory limitations & $145(15.92 \%)$ \\
\hline Intellectual disability, autism and sensory limitations & $8(0.88 \%)$ \\
\hline Missing data & $4(0.44 \%)$ \\
\hline \multicolumn{2}{|l|}{ Estimation of limitations in intellectual functioning } \\
\hline Mild & $189(20.75 \%)$ \\
\hline Moderate & $302(33.15 \%)$ \\
\hline Severe & $259(28.43 \%)$ \\
\hline Profound & $124(13.61 \%)$ \\
\hline Missing data & $37(4.06 \%)$ \\
\hline
\end{tabular}


Table 2 (on next page)

Effect sizes of latent mean differences for medical and behavioral needs' groups. 


\begin{tabular}{|c|c|c|c|c|}
\hline & \multicolumn{2}{|c|}{ Medical support needs } & \multicolumn{2}{|c|}{ Behavioral support needs } \\
\hline & Effect size & Significance & Effect size & Significance \\
\hline \multicolumn{5}{|c|}{ Factor A. Home } \\
\hline G1 vs. G2 & 0.81 & $<.001$ & 0.17 & .035 \\
\hline G1 vs. G3 & 1.56 & $<.001$ & 0.26 & .005 \\
\hline G1 vs. G4 & 1.99 & $<.001$ & 0.42 & $<.001$ \\
\hline G2 vs. G3 & 0.77 & $<.001$ & 0.09 & .369 \\
\hline G2 vs. G4 & 1.21 & $<.001$ & 0.26 & .013 \\
\hline G3 vs. G4 & 0.45 & $<.001$ & 0.20 & .076 \\
\hline \multicolumn{5}{|c|}{ Factor B. Community } \\
\hline G1 vs. G2 & 0.62 & $<.001$ & 0.23 & .005 \\
\hline G1 vs. G3 & 1.13 & $<.001$ & 0.36 & $<.001$ \\
\hline G1 vs. G4 & 1.36 & $<.001$ & 0.54 & $<.001$ \\
\hline G2 vs. G3 & 0.57 & $<.001$ & 0.13 & .187 \\
\hline G2 vs. G4 & 0.82 & $<.001$ & 0.32 & .003 \\
\hline G3 vs. G4 & 0.28 & .033 & 0.24 & .039 \\
\hline \multicolumn{5}{|c|}{ Factor C. School participation } \\
\hline G1 vs. G2 & 0.65 & $<.001$ & 0.24 & .004 \\
\hline G1 vs. G3 & 1.21 & $<.001$ & 0.37 & $<.001$ \\
\hline G1 vs. G4 & 1.50 & $<.001$ & 0.61 & $<.001$ \\
\hline G2 vs. G3 & 0.62 & $<.001$ & 0.13 & .183 \\
\hline G2 vs. G4 & 0.94 & $<.001$ & 0.39 & $<.001$ \\
\hline G3 vs. G4 & 0.34 & .009 & 0.32 & .005 \\
\hline \multicolumn{5}{|c|}{ Factor D. School learning } \\
\hline G1 vs. G2 & 0.46 & $<.001$ & 0.19 & .019 \\
\hline G1 vs. G3 & 0.81 & $<.001$ & 0.26 & .005 \\
\hline G1 vs. G4 & 1.08 & $<.001$ & 0.49 & $<.001$ \\
\hline G2 vs. G3 & 0.39 & $<.001$ & 0.07 & .483 \\
\hline G2 vs. G4 & 0.69 & $<.001$ & 0.31 & .004 \\
\hline G3 vs. G4 & 0.33 & .012 & 0.27 & .018 \\
\hline \multicolumn{5}{|c|}{ Factor E. Health and safety } \\
\hline G1 vs. G2 & 0.52 & $<.001$ & 0.12 & .132 \\
\hline G1 vs. G3 & 0.92 & $<.001$ & 0.36 & $<.001$ \\
\hline G1 vs. G4 & 1.18 & $<.001$ & 0.57 & $<.001$ \\
\hline G2 vs. G3 & 0.45 & $<.001$ & 0.23 & .015 \\
\hline G2 vs. G4 & 0.75 & $<.001$ & 0.45 & $<.001$ \\
\hline G3 vs. G4 & 0.33 & .012 & 0.27 & .021 \\
\hline \multicolumn{5}{|c|}{ Factor F. Social } \\
\hline G1 vs. G2 & 0.53 & $<.001$ & 0.27 & .001 \\
\hline G1 vs. G3 & 0.85 & $<.001$ & 0.55 & $<.001$ \\
\hline G1 vs. G4 & 1.09 & $<.001$ & 0.83 & $<.001$ \\
\hline G2 vs. G3 & 0.35 & .002 & 0.28 & .004 \\
\hline G2 vs. G4 & 0.62 & $<.001$ & 0.58 & $<.001$ \\
\hline G3 vs. G4 & 0.29 & .029 & 0.36 & .002 \\
\hline \multicolumn{5}{|c|}{ Factor G. Advocacy } \\
\hline G1 vs. G2 & 0.46 & $<.001$ & 0.15 & .071 \\
\hline G1 vs. G3 & 0.79 & $<.001$ & 0.35 & $<.001$ \\
\hline G1 vs. G4 & 1.09 & $<.001$ & 0.55 & $<.001$ \\
\hline G2 vs. G3 & 0.36 & .002 & 0.20 & .037 \\
\hline G2 vs. G4 & 0.69 & $<.001$ & 0.42 & $<.001$ \\
\hline G3 vs. G4 & 0.36 & .007 & 0.26 & .024 \\
\hline
\end{tabular}

